http://dx.doi.org/10.22187/rfd2018n44a10

Doctrina

\title{
Ricardo Oliveira Rotondano ${ }^{3}>$ \\ Entre monogamia e poliamor: o futuro da família no Brasil
}

Entre monogamia y poliamor: el futuro de la familia en Brasil

Between monogamy and polyamory: the family's future in Brazil

Resumo: O modelo de família ocidental tradicional, que durante séculos vigorou como única forma de convivência afetiva válida na sociedade, tem as suas concepções de legitimidade moral universal combatidas pelos pressupostos pós-modernos. As transformações de cunho filosófico-social ocorridas na sociedade ocidental contemporânea colocam em evidência a contestação de antigos dogmas supostamente universais, como a obrigatoriedade da forma monogâmica de convivência amorosa. Neste âmbito, surgem novos modelos de organização familiar e de afetividade, todos eles válidos e legítimos segundo uma ordem que se propõe pluralista e intercultural, que valoriza a diversidade e a diferença. Neste interim, as relações poliamorosas ganham cada vez mais destaque, despontando como práticas socioculturais que desafiam a supremacia histórica da entidade familiar monogâmica no ocidente.

Palavras-chave: poliamor, monogamia, família, pós-modernidade.

Resumen: El modelo de familia occidental tradicional, que durante siglos ha sido la única forma válida de convivencia afectiva en la sociedad, tiene sus concepciones de legitimidad moral universal confrontadas por los presupuestos posmodernos. Las transformaciones de cuño filosófico-social ocurridas en la sociedad

$\leftrightarrow$ Doutorando em Direito pela Universidade Federal do Pará (UFPA). Mestre em Direito pela Universidade de Brasília (UnB). Pós-graduado em Direito Constitucional pela Universidade Gama Filho. Bolsista da CAPES. Advogado.

$\bowtie$ rotondanor@gmail.com 
occidental contemporánea ponen en evidencia la respuesta de antiguos dogmas supuestamente universales, como la obligatoriedad de la forma monogámica de convivencia amorosa. En este ámbito surgen nuevos modelos de organización familiar $y$ de afectividad, todos ellos válidos y legítimos según un orden que se propone pluralista e intercultural, que valora la diversidad y la diferencia. En el interin, las relaciones poliamorosas ganan cada vez más destaque, emergiendo como prácticas socioculturales que desafian la supremacía histórica de la entidad familiar monogámica en occidente.

Palabras clave: poliamor, monogamia, familia, posmodernidad.

Abstract: The traditional western family model, wich for centuries has been the only valid form of affective coexistence in society, has its conceptions of universal moral legitimacy opposed by postmodern presuppositions. The philosophical-social transformations that took place in contemporary western society highlight the challenge to ancient supposedly universal dogmas, such as the compulsory monogamous form of loving coexistence. In this context, new models of family organization and affectivity emerge, all of them valid and legitimate according to a pluralistic and intercultural order that values diversity and difference. In the meantime, polyamor relations gain increasing prominence, emerging as sociocultural practices that challenge the historical supremacy of the monogamous family entity in the West.

Keywords: Polyamory, Monogamy, Family, Postmodernity.

Recibido: 20170602

Aceptado: 20180206 


\section{A família monogâmica no contexto histórico ocidental}

O termo "família" é de origem latina, tendo surgido na Roma Antiga derivada de famulus, que significa "servidor", não obstante conter significado diferente do que atualmente entendemos por esta palavra. Pois bem. Maria Engrácia Leandro ensina que, na Roma Antiga, "família" referia-se ao conjunto dos escravos e dos servidores, mas também a toda a domus (casa); "isto é, todos os indivíduos que vivem sob o mesmo tecto e os bens patrimoniais pertencentes a essa casa, numa hierarquia que mantinha, por um lado, o senhor e, por outro, a mulher, os filhos e os servidores, vivendo sob a sua dominação" (Leandro, 2006, 52).

A referida autora enuncia ainda que "família" chegou a significar, por extensão, os agnati - parentes pertencentes à linha paterna - e os cognati parentes concernentes à linha materna, assim como o conjunto dos parentes unidos pelo mesmo laço sanguíneo. Contemporaneamente, houve a reunião destas diversas unidades de parentesco, sendo alcunhada de família alargada ou parentela; seja como for, tais unidades de parentesco tem variado de extensão conforme as diferentes localidades, as épocas, os grupos sociais e as circunstâncias dentro das quais estão inseridas (Leandro, 2006, 52).

Como aponta Thomas Burton Bottomore $(2008,164)$, a entidade "família" é um fenômeno social universal, que exerce funções fundamentais para a vida humana. É o que igualmente aduz Anthony Giddens $(2001,99)$, entoando que a família é uma instituição básica da sociedade civil. Inegável atestar, desse modo, que a família guarda com a sociedade uma intrínseca relação de fundamentalidade. Entretanto, tal preceito não conduz necessariamente à conclusão de que a família possua a mesma estrutura em locais e épocas distintos; pelo contrário, os grupos familiares guardam diferenças substanciais históricas em sua formação (Bottomore, 2008, 166). Assim sendo:

Historicamente, o que podemos dizer de mais fundamental, é que a família, sendo uma instituição ancestral, universal, de formação multi- 
variada e culturalmente determinada, tem sabido resistir e adaptar-se a todas as transformações e mutações familiares e sociais, tendo ela própria participado, enquanto sujeito-actor, nessa mesma dinâmica social ao longo dos tempos. Ora, de uma tal observação pode retirar-se um corolário bem interessante: por todo o lado, a família é uma instituição basilar a ponto de que, até ao presente, nenhuma sociedade consegue passar sem ela, apesar de todas as transformações e mesmo mutações, os pessimismos, os discursos sobre a crise da família e até de alguns considerarem que uma sociedade sem família é possível (Leandro, 2006, 52).

Não obstante alguns autores reconhecerem a monogamia como única modalidade de entidade de família na história (Roudinesco, 2002, 16-18), existem formas de convivência que extrapolam o modelo binário de relação homem-mulher, tanto em períodos históricos anteriores como também na atualidade. Nas últimas décadas, ganhou força no seio dos países ocidentais a tese alcunhada "poliamor", que condiz com as relações afetivas entre múltiplas pessoas - seja em uma união estável e duradoura, ou em relacionamentos casuais e esporádicos. Esta corrente de novos adeptos às formas plurais de afeto - que, apesar de historicamente existentes, somente em períodos mais recentes foram colocadas em debate público - põem em xeque a dominação secular do padrão monogâmico ocidental.

Antes de adentrar a questão do poliamor, é preciso tecer algumas considerações sobre a monogamia e a sua constituição como modelo de organização familiar ocidental. Entendida historicamente como "o sistema de constituição familiar pelo qual o homem possui uma só esposa ou companheira e a mulher apenas um único marido ou companheiro" (Quadros, 2004, $\mathrm{s} / \mathrm{p}$ ), a monogamia vigorou como forma afetiva obrigatória no ocidente até o século passado, quando enfrentou uma dupla contestação. A típica relação europeia ocidental cristã predominante ao longo dos últimos dez séculos, que engloba a união entre um homem e uma mulher, teve a sua supremacia posta em questionamento pelo crescente movimento homossexual.

A partir do engajamento coletivo em torno das suas demandas, o movimento homossexual conseguiu paulatinamente o reconhecimento dos seus direitos frente aos Estados ocidentais, que negavam aos indivíduos a possibilidade de constituir uma união civil pública e fruir de todas as conse- 
quências institucionais deste ato. Embora tais conquistas tenham se iniciado e se disseminado com força e propriedade, a resistência de certos grupos retrógrados e conservadores impedem o reconhecimento de tais direitos em muitos Estados ocidentais, nos quais o engajamento LGBTI persiste.

Neste caminho, inferir do conceito de família monogâmica somente a relação afetiva entre heterossexuais é, inegavelmente, atribuir a esta acepção um caráter excludente e discriminatório. A paulatina conquista dos grupos homossexuais à aceitação social e estatal quanto à sua união familiar não pode ser negada por qualquer trabalho científico que se proponha coerente e libertário. O Brasil não se configura como exceção: cabe enunciar o recente julgamento da ADI 4.277, no qual o Supremo Tribunal Federal reconheceu a união homoafetiva como legítima entidade familiar.

Assim sendo, o conceito de família monogâmica se refere a uma relação entre duas pessoas - de mesmo sexo ou de sexos distintos, em uma visão mais atual e inclusiva. De acordo com preceitos pacificados no âmbito jurídico - e, de certo modo, no contexto social - o fator "fidelidade" é relevante nesta seara: a monogamia configura a abstenção mútua entre os parceiros em se relacionarem com demais indivíduos, seja ocasionalmente ou de forma frequente (Diniz, 2004, 125; Gonçalves, 2008, 174; Pereira, 2004, 170; Rodrigues, 2004, 126; Venosa, 2004, 161). Demais formas de relacionamento não-poligâmicas incorrem no poliamor, sobre o qual este trabalho discorrerá em capítulo posterior.

Resta, ainda, esclarecer o contexto histórico dentro do qual a monogamia foi alçada ao modelo unicamente válido no ocidente. A tese mais difundida acerca do surgimento do paradigma monogâmico associa tal evento ao início da concorrência inerente à propriedade privada. Sergio Lessa (2012, 43) explica que em tempos remotos, quando o ser humano ainda vivia em comunidades sem uma organização institucional burocrática, os integrantes daqueles grupos mantinham a sua subsistência através do trabalho cooperativo, repartindo igualitariamente os frutos daquela produção comunitária. Com o desenvolvimento de novas formas e ferramentas de produtividade, o trabalho se tornou mais eficiente, gerando o excedente da produção. Iniciamse, então, as disputas pela apropriação privada deste excedente pelos sujeitos. 
A transição da sociedade comunitária originária para a sociedade da propriedade privada deveria, essencialmente, abolir as relações afetivas simultâneas entre os indivíduos. Tal necessidade surge, conforme prega Friedrich Engels $(1997,62)$, ante a exigência de controle da propriedade dentro de cada família, posto que, adotando-se a monogamia, delimita-se estritamente a prole de cada sujeito. Dessa forma, "o Estado organiza a sociedade e, pelo casamento monogâmico, organiza a família" (Lessa, 2012, 44); estabelece-se, assim, a monogamia como principal entidade familiar ocidental, de modo a controlar a sexualidade feminina para que não pairassem dúvidas sobre os herdeiros.

A mulher, então, é destituída das suas funções produtivas, tendo a sua vida social extremamente reduzida, ante a necessidade de controlar sua sexualidade. Conforme aduz Sergio Lessa $(2012,43)$, “o feminino se converte em uma existência privada, centrada nela própria, localista: 'do lar'. Sua vida se resume à ordem e à produção doméstica". (1) Institui-se a família monogâmica patriarcal, com o homem a deter o controle da sociedade - propriedade privada, Estado, comércio. Ante tal panorama, os modelos afetivos que extrapolavam a monogamia passam a ser encarados como nocivos à manutenção da ordem social.

Soma-se a este cenário a ascensão histórica da religião cristã no ocidente, com bases estritamente monogâmicas, e que eleita a religião oficial do Império Romano, alastrou-se com propriedade pelas nações europeias e, posteriormente, pelas colônias do chamado "novo mundo" (Rotondano, 2016, 93). Dessa forma, os países norte-americanos e latino-americanos herdaram dos povos invasores a religião cristã - nas suas mais variadas vertentes e desambiguações - que prosseguiram ao longo do tempo como seitas dominantes entre as referidas populações (Rotondano, 2013, 226), que consequentemente adotaram o modelo monogâmico.

Não obstante a majoritária e evidente adesão à monogamia, desponta no ocidente não somente a prática de relações não-poligâmicas - que historicamente sempre existiram - mas o debate público em torno do reconhecimento social e institucional frente a estas relações afetivas. Neste quesito, as teorias acerca do poliamor ganham corpo, gerando discussões de peso entre estudiosos dos mais diversos ramos sociais. $\mathrm{O}$ entendimento acerca dos caracteres do poliamor, ainda que de modo sucinto, é tarefa imprescindível para a 
continuidade das ponderações realizadas neste escrito.

\section{Breves considerações sobre o poliamor}

O conceito de poliamor está ligado inerentemente a um modelo que extrapola as relações binárias monogâmicas (Barker, 2005, 75), envolvendo uma ou mais pessoas adicionais dentro deste quadro afetivo. Ao contrário do que parcela dos estudos apresenta, poliamor não se confunde com poligamia - em que o núcleo familiar agrega três ou mais pessoas. ${ }^{(2)}$ Não é necessário que haja uma pluralidade de pessoas dentro de uma relação estável, embora tal situação se enquadre no conceito de poliamor, como ocorre nas relações paralelas ou concomitantes. Para que a relação se enquadre no contexto poliamorista, basta que os conviventes abdiquem da forma monogâmica exclusivista de afetividade; neste quadro, os relacionamentos abertos também são uma forma de poliamor (Pilão y Goldenberg, 2013, 64) - ainda que o núcleo da relação afetiva seja constituído por duas pessoas.

Nesse quesito, interessante a classificação proposta por Antonio Pilão $(2015,393)$, sobre os modelos de poliamor abertos e os fechados. Os relacionamentos poliamorosos abertos são configurados pela liberdade que os indivíduos envolvidos na relação têm de se envolverem afetivamente com outras pessoas não integradas à relação nuclear afetiva. Por sua vez, os relacionamentos fechados são aqueles que se assemelham à poligamia, em que o poliamor se restringe às relações afetivas já existentes e compartilhadas igualmente por todos os sujeitos envolvidos - três ou mais pessoas se relacionando mutuamente.

No que, então, consiste o poliamor? A adesão à forma poliamorosa de afetividade envolve uma escolha consciente à prática de relações eticamente não-monogâmicas. Elizabeth F. Emens $(2003,5)$, nessa toada, elenca cinco princípios concernentes à prática dos indivíduos que optam pelo modelo poliamoroso: autoconhecimento, honestidade radical, consentimento, autopertencimento, além de privilegiar o amor e o sexo ao ciúme. Cada um destes elementos faz alusão a uma característica necessária para a prática poliamorosa de modo harmonioso nos seus mais diferentes modelos.

$\mathrm{O}$ autoconhecimento se refere não somente à modalidade de afetividade alcunhada de orientação sexual, mas como uma incessante reflexão acerca 
dos sentimentos decorrentes das relações amorosas e sexuais do sujeito. Envolve o questionamento e o aprendizado sobre o ciúme e a possessão, ponderando criticamente sobre o sistema monogâmico culturalmente imposto e entendendo com maior profundidade como se desenvolvem os seus sentimentos e a sua visão de mundo frente a novas experiências de afetividade múltipla e plural que não condizem com o padrão hodiernamente posto. ${ }^{(3)}$

A honestidade é um elemento primordial para configurar a relação poliamorosa (Klesse, 2008, 571), vez que tal requisito - em conjunto com o consenso - é o que distingue tais relacionamentos das uniões monogâmicas em que há relações extraconjugais ocultas, em que ocorre a traição. A teoria acerca da infidelidade cai por terra quando encaramos este requisito básico, vez que o conceito de fidelidade conduz àquele sujeito que cumpre com os compromissos pactuados, que é verdadeiro, que não engana o cônjuge (Rios, 2012, 270). Não há o engodo, a ilusão, a mentira: toda a relação poliamorosa é baseada na sinceridade, na lealdade, na abertura consciente para um relacionamento não monogâmico. Enquanto a honestidade reflete a comunicação franca sobre a opção não-monogâmica, a aceitação expressa pelas demais pessoas partícipes da relação poliamorosa é o que, em segundo plano, configura o consenso.

Adentrar uma relação afetiva não significa que a pessoa passe a pertencer à sua parceira ou seu parceiro. O elemento da autopossessão se coaduna exatamente com este fator de posse ou propriedade nas relações, que comumente permeia as uniões monogâmicas (Pilão, 2015, 411). Por sinal, este é um elemento historicamente utilizado pelos homens para a submissão da mulher, objetificando-a e suprimindo a sua sexualidade. O critério da autopossessão prega a liberdade inerente aos sujeitos que se arvoram em uma relação afetiva, de manterem o seu espaço de decisão e ação resguardados das tentativas de dominação alheias.

Por fim, deve-se desmistificar a hodierna associação entre ciúme e amor - quem ama, tem ciúme. Os poliamoristas refletem sobre a incisiva convergência entre os sentimentos de posse e de ciúme, entoando que se atrelar somente a uma parceira ou parceiro por receio de perdê-la ou perdê-lo significa abrir mão de uma ampla gama de possibilidades amorosas e sexuais. Ao revés, as adeptas e adeptos do poliamor valorizam a compersion (Emens, $2003,45)$, que pode ser traduzido como o sentimento de satisfação ao perce- 
ber a felicidade da parceira ou parceiro e de identificar tal pessoa sendo amada por outros indivíduos.

Entretanto, o poliamor ainda enfrenta sério preconceito social ao ser comparado com a poligamia patriarcal praticada em nações islâmicas. ${ }^{(4)}$ Segundo o lexicógrafo Francisco da Silveira Bueno (1996, 513), a poligamia é definida como o "matrimônio de uma pessoa com muitas outras". Em outros termos, a poligamia se caracteriza quando três ou mais pessoas se encontram em uma mesma relação conjugal. Nesse sentido, a poligamia seria um conceito amplo, que se subdivide em duas principais facetas: a poliandria - em que uma mulher convive com mais de um homem - e a poliginia - um homem com mais de uma companheira.

Apesar das referidas subdivisões, o presente trabalho abarca a possibilidade da formação de uma entidade familiar poligâmica que não se enquadre em quaisquer destes conceitos: dois homens e três mulheres, duas mulheres e quatro homens, convivência afetiva entre quatro mulheres - as possibilidades são infinitas. Seria, digamos, um conceito latu sensu acerca da poligamia, enquadrando-a em seu significado original - visto que "poligamia" é um termo de origem grega, que significa muitos casamentos. Negamos, pois, o enquadramento da poligamia estritamente como poliandria ou poliginia; a poligamia em seu sentido mais amplo não pressupõe, como querem alguns, a "assimetria de gênero, ou seja, há um único polígamo em cada relação" (Pilão y Goldenberg, 2012, 64).

Érica Veras $(2013,71-72)$ é enfática ao entoar que a poligamia sempre existiu, seja de modo explícito ou de forma velada. A novidade quanto ao referido campo se refere justamente à recente visibilidade que se tem concedido ao tema, inclusive na busca por uma base legal para que sejam reconhecidos na legislação brasileira e mundial, e por conta da visibilidade recente que o modelo poliamoroso em geral tem obtido. A existência da poligamia institucionalizada é frequentemente encontrada em países da parte oriental do globo, em especial as nações islâmicas e muçulmanas (Pilão y Goldenberg, 2012, 64). Entretanto, é possível identificar Estados predominantemente cristãos que sejam tolerantes com a poligamia, como é o caso de Moçambique, relatado por Ana Beatriz Matte Braun $(2008,9)$ : 
O leitor não familiarizado com a realidade africana não deve se chocar. Qualquer um que acompanhe a vida aqui percebe que a poligamia é prática relativamente comum. Não causa espanto a ninguém ouvir dizer que determinado homem tem duas ou três mulheres. No entanto, é perceptível a leve tensão que a poligamia causa em locais considerados mais ocidentalizados, como os centros urbanos e até mesmo o meio acadêmico. É como se houvesse uma atmosfera de recriminação constante - a poligamia não faz parte do mundo considerado civilizado, o mundo que o africano teve que adotar por força da colonização.

Não obstante os mais variados e diversos arranjos familiares, percebemos que o casamento monogâmico ainda permanece como a forma de organização nuclear da família que predomina atualmente (Oliveira, 2009, 66). O conservadorismo arraigado em grande parcela doutrinária costuma embasar a constatação de que a monogamia seria uma categoria antropológica e sociológica contraposta e superior aos demais modelos não-monogâmicos (Adovasio et. al., 2008). Nesse sentido, costuma-se disseminar a ideologia de que não seria possível haver vida civilizada sem a organização monogâmica da família (Roudinesco, 2002, 21-22).

Nessa toada, Nayara Hakima D. de Oliveira $(2009,84)$ aduz ser imprescindível para a reflexão acerca da família a desconstrução de conceitos socialmente prontos, almejando o desprendimento das visões de mundo historicamente arraigadas para que se possa entender as novas configurações familiares. A autora entende que o desafio de buscar reflexões sobre os novos conceitos de família acaba se configurando como uma experiência proveitosa e enriquecedora, abrindo o campo de possibilidades da sociedade contemporânea e rompendo paradigmas já sedimentados.

Tal posicionamento guarda estreita relação com a temática que abordaremos adiante: o pós-modernismo. Em decorrência de tal movimento históricosocial, não somente o dogma familiar monogâmico, mas as "verdades absolutas" em geral se encontram sob grave ameaça. A referida reflexão se reveste de importância ante a obrigatoriedade do sistema familiar monogâmico existente em território brasileiro. Questionar a atual conjuntura social e jurídica e ponderar sobre novas alternativas à família são propostas do mais alto e relevante teor, que pretendemos efetuar a seguir. 


\section{O pós-modernismo e a família}

A concepção do que seria este fenômeno denominado pós-modernismo não é tarefa fácil - havendo mesmo dúvidas acadêmicas sobre a efetiva emergência ou não da pós-modernidade. ${ }^{5}$ Krishan $\operatorname{Kumar}(2006,142)$ reconhece tal dificuldade, aduzindo que tal construção seria útil, no entanto avessa à maioria das práticas dos pós-modernistas, visto que estes rejeitam a tendência moderna em conceituar. Segundo Kumar, esta aversão se deve ao enclausuramento reflexivo-crítico provocado pela prática de definir, apegando-se a um modelo de racionalidade e objetividade tipicamente modernista.

O principal ponto da crítica pós-moderna, segundo Jeni Vaitsman (1994, 37 ), está no fato de que o discurso racional moderno, que se pretendia universal, acabou privilegiando os discursos oriundos dos grupos hegemônicos no cenário histórico mundial. ${ }^{(6)}$ É justamente contra a imposição da cultura ocidental contemporânea que o pós-modernismo emprega um caráter desconstrutivo em seus modelos discursivos e culturais. Para a referida autora: "Desconstruir, enquanto noção pós-moderna por excelência, recebeu o significado de provocar uma ruptura em algo que parecia unificado" (Vaitsman, 1994, 38).

Seguindo o referido entendimento, o indivíduo racional e autônomo proveniente da teoria liberal foi dissolvido - ou melhor, desconstruído - em uma multiplicidade de sujeitos parcialmente coincidentes e mutuamente incompatíveis, tendo diferentes identidades e interesses. Nesses termos, a "razão" ou a "verdade" acabam se tornando impossíveis, porque são objetos irreais (Kumar, 2006, 172). O objetivo da pós-modernidade, neste aspecto, é revalorizar preceitos e modos de vida particularistas que foram esquecidos e rejeitados pela racionalidade dominante, proveniente das nações historicamente vencedoras no cenário global.

A desconstrução pós-modernista é vista por Krishan Kumar (2006, 146148) como uma reação cultural ao modernismo. Segundo o autor, o pós-modernismo emerge após o movimento modernista abandonar o seu élan revolucionário; o modernismo perdeu a capacidade de desafiar e questionar antigos paradigmas. Vigora então, no modernismo, o princípio da autoridade. Como consequência, rompendo com o paradigma vigente, no pós-modernismo impera o princípio da anarquia, que implica uma aposta histórica no ecletismo, na pluralidade, na mudança, na transição. 
Esta é igualmente a posição adotada por Boaventura de Sousa Santos $(2002,29)$. O sociólogo português reflete que "as promessas da modernidade, por não terem sido cumpridas, transformaram-se em problemas para os quais parece não haver solução". Não há soluções modernas para os problemas modernos; somente a pós-modernidade mostra-se capaz de resolver tais questões. $\mathrm{O}$ autor adota posição que denomina pós-modernidade inquietante ou de oposição, entoando que a problemática oriunda da modernidade deve ser confrontada e substituída pelas soluções inovadoras e revolucionárias fruto da pós-modernidade, sendo esta a única via possível para a construção e edificação de uma teoria crítica.

Ademais, no pós-modernismo, o pluralismo e a diversidade inerentes à sociedade intercultural contemporânea não são rejeitados (Kumar, 2006, 140). Os teóricos modernistas acreditavam no progresso e na ciência, que trariam para todos os campos - seja na política, economia, história - conhecimentos evoluídos a tal ponto que se tornassem únicos, universais. A esperança na obtenção de verdades absolutas para todos os tempos e para todos os povos entra em completa descrença. $\mathrm{O}$ decurso temporal revela a impossibilidade humana de obtenção de respostas últimas para as inquietudes do mundo e da sua própria existência:

Relembre-se, como em outro contexto, que as verdades teológicas, metafísicas e racionais que sustentaram durante séculos as expressões de saber, de poder e de racionalidade dominantes não conseguem mais responder inteiramente às inquietações e às necessidades da presente etapa de globalização das relações humanas. Os modelos culturais, normativos, e instrumentais que fundamentaram o mundo da vida, a organização social e os critérios de cientificidade tornaram-se insatisfatórios e limitados. A crescente descrença em modelos filosóficos e científicos que não oferecem mais diretrizes e normas seguras abre espaço para se repensarem padrões alternativos de fundamentação. Os paradigmas que produziram um ethos, marcado pelo liberalismo individual, pelo racionalismo instrumental e pelo formalismo positivista, bem como os que mantiveram a logicidade do discurso filosófico, científico e jurídico têm sua racionalidade questionada e substituída por novos modelos de referência (Wolkmer, 2001, 232). 
Os pós-modernistas, desse modo, preferem acatar a tese de que existem verdades parciais, variáveis ao longo do espaço e do tempo. Aceitam e valorizam as experiências particularizadas de grupos e indivíduos, rejeitando as ideias totalizantes e unificadoras, seja no aspecto cultural, social, biológico e/ou técnico (Vaitsman, 1994, 43). Sendo assim, quando se fala em pós-moderno, nos mais variados campos - na arte, na arquitetura, na cultura, no texto literário, na economia, na política ou na família - está-se discorrendo acerca da aceitação da coexistência e da mistura de códigos e de mundos, do reconhecimento da heterogeneidade que existe na sociedade contemporânea. Falase, sobretudo, de uma heterogeneidade que atualmente se quer reconhecida como legítima. No pós-modernismo, a pluralidade, o particular e o local se contrapõem a ideias de unidade, de geral e universal, que constituem o eixo do modernismo (Vaitsman, 1994, 43).

Sendo assim, para a teoria pós-moderna, todo e qualquer conhecimento crítico deve começar pela crítica do conhecimento, em uma atividade reflexivo-epistemológica radical. O conhecimento-regulação, predominante na era do conhecimento moderna, cede espaço ao conhecimento-emancipação. Boaventura de Sousa Santos (2002, 29-30) explica que "nesta forma de conhecimento conhecer é reconhecer e progredir no sentido de elevar o outro da condição de objeto à condição de sujeito". O autor denomina este modelo de conhecimento-reconhecimento de "solidariedade".

Ainda conforme Boaventura de Sousa Santos $(2002,30)$, mais do que a internalização do conhecimento científico disseminado, deve-se investir no questionamento das verdades postas e na procura por formas de conhecimento que valorizem o princípio da solidariedade. Apesar deste fato, Sousa Santos ressalta que esta é uma barreira difícil de ser enfrentada e superada. As alternativas elaboradas pela teoria crítica moderna, como se sabe, historicamente não lograram sucesso. Segundo o referido autor, a sociedade contemporânea necessita de um pensamento alternativo de alternativas.

A pluralidade exaltada pelos pós-modernistas faz com que a ideia de uma cultura e identidade nacionais seja desfragmentada, dando espaço para as culturas minoritárias, com as mais distintas e diversas características. Desse modo, o pós-modernismo se baseia pela política da diferença, promovendo sociedades pluriétnicas e multifacetadas. A identidade de uma nação, por conseguinte, não é unitária, e sim fluida e mutável (Kumar, 2006, 159). Nesse 
sentido, qualquer tentativa de homogeneização cultural e social se caracteriza como uma ameaça ao modelo plural pós-moderno atualmente em ebulição.

Esta é igualmente a lição trazida pelo sociólogo paulista Octavio Ianni $(2001,86)$, ao entoar que "em lugar de um horizonte cultural único, homogêneo, sedimentado, descortina-se um horizonte cultural diversificado, múltiplo, em movimento". Segundo o referido autor, "na medida em que as diferentes sociedades, culturas, tradições, línguas e religiões encontram-se, tensionam-se e mesclam-se, emerge a pluralidade de perspectivas" (Ianni, 2001, 86). A homogeneidade de valores ético-culturais, tida como meta a ser alcançada pelos ideais modernistas se revela, em uma análise mais apurada, como incongruente com a valorização de modos de vida diversos - todos eles válidos.

Conforme explica o professor Krishan Kumar $(2006,159)$, a exaltação da pluralidade pelos pós-modernistas caracteriza o rompimento com um ambicioso - e, de certo modo, tirânico - ideal modernista de alcançar verdades últimas e universais, válidas para todos os povos e para todos os tempos. Kumar ensina que os investigadores e pesquisadores científicos devem ter ciência de que o seu papel coletivo não pode se pautar pela construção de preceitos por meio de uma visão universalizante e fechada, seguindo supostos princípios universais da razão, sob pena de negar a validade de demais formas de vida e de conhecimento:

Não existe nenhum princípio desse tipo. Os intelectuais têm de aceitar um papel mais modesto de intérpretes e intermediários de costumes e culturas, utilizando suas habilidades para ajudar comunidades a se entenderem reciprocamente. [...] Indivíduos e sociedades são muito menos determinados, muito mais livres para moldar seus próprios destinos, do que lhes permitia a teoria social clássica da modernidade (Kumar, 2006, 159).

O processo de transformação pós-modernista, inegavelmente, traz reflexos para o âmbito familiar. E não poderia ser diferente: o núcleo básico da sociedade, pois, é a família. As transformações sociais interferem indiscutivelmente dentro do seio familiar. Por sua vez, a valorização da "efemeridade, da fragmentação, da descontinuidade e do caótico, da mistura de códigos e de mundos" (Vaitsman, 1994, 51) - elementos estes trazidos pelo movimento pós-modernista - induz à conclusão de que em diferentes partes da sociedade atual, o con- 
ceito moderno de casamento e de família, amparado no individualismo patriarcal monogâmico, passou a conviver com uma concepção pós-moderna, dentro da qual a heterogeneidade, a efemeridade, a contextualidade de padrões e comportamentos se tornaram traços dominantes e legítimos.

Jeni Vaitsman $(1994,52)$ chega a afirmar que, diante de todo o discurso pós-moderno, não há mais um único e exclusivo modelo de família predominante na contemporaneidade. Vaitsman ensina que a influência do pósmodernismo na sociedade atual ocasionou o surgimento e a proliferação de diferentes formas de família, que constantemente se chocam e dialogam entre si. Segundo a referida autora, a família pós-moderna cada vez mais passa a acolher e legitimar socialmente novos padrões e formas de afetividade humana, sejam elas institucionalizadas ou não.

Jeni Vaitsman $(1994,52)$ realiza, ainda, uma reflexão sobre o cenário em que a instituição familiar está inserida dentro da sociedade brasileira. A pesquisadora expõe que no Brasil ocorreram alterações de caráter econômico, social, político, cultural, técnico, espacial e de gênero, de tal forma que foram produzidas diferenças tais que consequentemente originaram formas diversas de convivência afetiva entre os indivíduos. Como consequência, foram experimentadas modificações na identidade, na sexualidade e nos relacionamentos entre as pessoas: tem origem, então, um novo paradigma familiar.

\section{O novo paradigma familiar}

Apesar de todas as recentes transformações globais nas mais variadas esferas - cultural, política, econômica - o pensamento religioso predominante insiste em atribuir à família uma espécie de extraterritorialidade divina. Dizse que ela é sustentada por um aval divino, que de certo modo exime-a de temer a ação corrosiva do tempo. Sob tal prisma, "a família europeia-cristã tornou-se para o resto do tempo histórico o modelo acabado e último grito em matéria de organização familiar” (Bach, 1983, 104). Tal estrutura seria válida para todos os tempos e para todos os povos, não necessitando de qualquer reforma ou adaptação.

A realidade é outra, como aponta José Marcos Bach $(1983,106)$. A família, segundo o autor, não está - como qualquer outra instituição humana a salvo de mudanças histórico-culturais. A perspectiva imodesta e preten- 
siosa do pensamento religioso entra, no presente caso, em choque direto com a necessidade social de reformulação da antiga estrutura familiar. Segundo o autor, atrelar a legitimidade de uma forma de organização afetiva-familiar a preceitos ideológicos de modo dissociado às transformações da sociedade implica um direcionamento inescapável para ser ultrapassado pelo tempo.

Em semelhante sentido, Maria Engrácia Leandro (2006, 53) aduz que mais do que uma célula base ou um último refúgio contra as agressões externas, a família se caracteriza como uma entidade flexível e persistente, ao ser devidamente analisada tendo dela tomada certa distância histórica. Para a autora, ao invés de adotarmos uma postura pessimista e avaliarmos sob uma perspectiva de crise, mais proveitoso seria questionar acerca das mutações pelas quais a entidade familiar passou, derivadas das transformações sociais, econômicas, culturais, entre outras, produzidas ao longo dos séculos.

Ainda para José Marcos Bach $(1983,106)$, persistir na imposição, através da autoridade, de determinado tipo de família ou de convivência afetiva significa o mesmo que se colocar à margem da evolução e da história humana. De forma incisiva, o Bach preceitua que "a superproteção moral da família por parte das Igrejas cristãs dirige-se na realidade a um único tipo de família, precisamente àquele que já não se ajusta mais às novas necessidades sociais". Todas as alterações filosófico-sociais reclamam da família um reposicionamento estrutural que conflita frontalmente com o modelo estanque propagado pelas seitas religiosas de vertente cristã.

Tais mudanças no seio familiar são identificadas pelas comunidades cristãs ortodoxas como uma espécie de crise da família contemporânea. Tais grupos sociais insistem, por vezes, em investir em um processo dogmático-conservador, retroagindo aos antigos costumes familiares típicos da já superada família tradicional europeia cristã. Entretanto, a tentativa de resgate de um modelo retrógrado e único de família, contrariando múltiplos modelos de convivência afetiva oriundos da sociedade pós-moderna, está inevitavelmente fadada ao insucesso. Como aduz o pesquisador Anthony Giddens $(2001,102)$ :

Recapturar a família tradicional é uma tentativa destinada a malograr. [...] Não é de surpreender, portanto, que quando críticos direitistas falam da família tradicional eles não tenham de fato em mente, em absoluto, a família tradicional, mas um estado transnacional da família no pe- 
ríodo do pós-guerra imediato - a família (idealizada) da década de 1950. Naquela altura, a família tradicional tinha praticamente desaparecido, mas as mulheres ainda não haviam ingressado na força de trabalho em grandes números e as desigualdades sexuais permaneciam pronunciadas.

Durante séculos, o paradigma europeu-cristão monogâmico dominou o seio familiar ocidental. O rompimento com tais preceitos, no entanto, é uma necessidade prática, que já está em curso: a família da atualidade não mais se identifica com qualquer padrão pré-estabelecido. Não há como prever, ao certo, o que a desconstrução deste dogma histórico irá causar na sociedade vigente. A família está imergindo em um campo inteiramente novo, desconhecido. A perda de validade de valores e modelos da tradição e a incerteza em se tratando das mais recentes propostas que se apresentam acabam por desafiar a família a conviver com certa fluidez, abrindo um leque de possibilidades que valorizam a criatividade numa dinâmica do tipo tentativa de acerto e erro (Petrini y Cavalcanti, 2005, 42). ${ }^{(7)}$

São visíveis as profundas mudanças na estrutura da família e nos ordenamentos jurídicos de todo o mundo decorrentes da era pós-moderna. É cada vez mais comum encontrar modelos de família cujos integrantes compartilham atribuições e práticas estruturais, que constrastam com os antigos modelos tradicionais, cujos papéis eram rigidamente definidos (Oliveira, 2009, 68). Entre os inúmeros preceitos familiares progressistas, podemos citar o fim do princípio da indissolubilidade do casamento, a implementação da proteção jurídica e equiparação dos fillhos biológicos e adotivos, e o recente reconhecimento judicial e legislativo obtido pelos casais homoafetivos. $\mathrm{Na}$ atualidade, os juristas encontram-se diante de um direito de família que contempla múltiplas formas de vivência e convivência (Venosa, 2004, 21). ${ }^{(8)}$

O Brasil tem evidenciado, nesse sentido, um claro cenário de transição quanto aos antigos preceitos estanques do modelo monogâmico de família. Nos últimos anos, noticiaram-se atos corajosos de registros cartoriais de uniões poliamorosas entre conviventes que, não obstante o temor da repressão social, arvoraram-se em estabelecer a declaração legal da sua união para garantir mutuamente os direitos que derivam de um relacionamento afetivo. Nesse quesito, as transformações sociais e a emergência de novas práticas familiares reclamam do direito a readaptação dos seus institutos, rompendo 
a edificação de preceitos jurídicos tidos como tradicionais e adequando-se aos reclames dos conviventes poliamorosos (Silva, 2016).

José Marcos Bach $(1983,112)$ preleciona ainda que a contração da família é um processo histórico-evolutivo, que precisa ser correlacionado ao fenômeno de emancipação humana frente a diversas formas de repressão e alienação, típicos de nossa época. Bach discorre sobre a alienação moral da família, aduzindo que esta viola de pronto o princípio da autonomia. Segundo o referido autor, as modalidades de religiosidade e espiritualidade que negam as formas de autonomia moral do indivíduo e da família são, em verdade, ameaças à realização plena dos sujeitos conviventes.

Discorrendo sobre a importância da autonomia moral, Bach (1983, 113) escreve que "a autonomia, ao invés de representar um obstáculo à solidariedade, gera formas superiores de unidade moral. Ela conduz natura sua à comunhão das consciências". Desse modo, conclui-se que a autonomia moral da consciência é conditio sine qua non para que haja a comunhão afetiva. Para Bach, por obra da consciência livre e autônoma, as mais diversas formas de interdependência acabam se transformando em amor e solidariedade, mesmo aquelas mais rudimentares.

O histórico de transformações das sociedades e da família conduz ao paulatino amadurecimento dos preceitos que revestem a sua estrutura e, mais do que isso, à legitimação popular da validade dos múltiplos modelos de relacionamento e convivência. Especificamente no caso das sociedades ocidentais, a família acabou passando do predomínio das organizações estatais de poder centralizado para sistemas populares democráticos, em que se valoriza a liberdade, a igualdade de oportunidades, a racionalidade e o indivíduo: enquanto a tradição perde importância, a afetividade sobrepõe-se ao status de essencialidade (Leandro, 2006, 52-53).

Bach (1983, 114-115) reflete também sobre a origem da família, associada pela moral cristã às leis da natureza. Seguindo o raciocínio cristão, a família seria o resultado, pois, da interação de um complexo de determinismos biofisiológicos. Para o autor, porém, esta é uma concepção equivocada, tendo em vista que a teoria naturalista da família não contém qualquer base argumentativa coerente. É, nesse sentido, um erro crasso de perspectiva ligar a ontogênese da família ao despertar de um certo instinto natural: as implica- 
ções de ordem moral que uma ideologia naturalista desta ordem acarreta são simplesmente desastrosas.

Não se pode negar, desta forma, que a família sofreu e ainda sofre um rigoroso processo de transformação social e institucional. $\mathrm{O}$ antigo paradigma europeu-cristão familiar, baseado estritamente na monogamia heterossexual indissolúvel, perdeu o posto de modelo único de organização familiar aceito e praticado pela sociedade contemporânea, enfrentando atualmente a concorrência de múltiplas formas de afetividade. Diante de todas essas mudanças históricas e culturais no contexto da família, João Carlos Petrini e Vanessa R. S. Cavalcanti $(2005,51)$ enunciam:

Nesse ambiente de profundas mudanças que atingem a família e que continuam a suceder-se em ritmo acelerado, os contextos familiares existentes, na pluralidade de configurações historicamente observáveis, parecem ser impelidos a uma permanente reformulação dos significados vividos, das metas propostas e dos métodos para que a convivência familiar continue sendo fonte de satisfação e de esperança quanto à utilidade dos sacrifícios enfrentados.

Tais transformações paradigmáticas no seio familiar inegavelmente conduzem a reflexos dentro do campo jurídico. Nessa seara, Luiz Edson Fachin $(2003,306-307)^{9}$ entende não existir mais uma única definição para o ente familiar, posto que a família se tornou plural. Para o autor, a família já não continha mais uma única definição no campo das relações sociais. Atualmente, tal pluralidade alcança igualmente o plano do direito familiar. Por conseguinte, o direito de família brasileiro tem os seus rumos indefinidos, tornando-se "mais fonte de reflexão e menos de conclusões" (Fachin, 2003, 306-307).

\section{Considerações finais}

A história da família ocidental demonstra o predomínio do modelo monogâmico ao longo dos séculos. Desde o amparo do Cristianismo como religião oficial do Império Romano por Constantino, a proibição das demais formas de convivência afetiva proliferaram-se pelo continente europeu e, posteriormente, pelas suas possessões territoriais - a América e a África. O preceito heterossexual monogâmico familiar se tornou um forte e poderoso dogma cultural, que 
as distintas comunidades nacionais disseminaram hereditariamente ao longo das suas gerações.

Nas últimas décadas, entretanto, formas alternativas de convivência familiar têm reclamado o seu espaço de legitimidade frente à sociedade. A batalha pelo reconhecimento dos direitos dos casais homossexuais se mostrou, nessa seara, um dos grandes desafios postos frente à comunidade ocidental e que, ainda hoje, enfrenta severa resistência de certos grupos organizados. Nesse ínterim, as modalidades de relacionamento não monogâmicas despontam não como uma nova prática, mas sim como um novo tema alçado ao debate público, que ainda não recebeu a devida atenção pela sociedade e pelas instituições políticas.

O chamado poliamor reflete, pois, a opção clara pela superação da monogamia como única forma de relacionamento afetivo humano. Há mais do que uma vinculação binária obrigatória entre sujeitos: as múltiplas formas de sexualidade e convivência que extrapolam o amor entre duas pessoas são igualmente válidas, não merecendo qualquer repressão social ou estatal. A expansão das práticas poliamorosas em todo o ocidente e no Brasil impulsionou o debate público acerca da sua legitimidade, que cada vez mais ganha corpo e relevância, em especial na seara do direito de família brasileiro.

As modalidades de afetividade poliamorosas se coadunam com o momento de reflexão filosófico-racional acerca de dogmas e paradigmas estabelecidos historicamente e, mais do que isso, da capacidade humana de alcance de verdades absolutas e imutáveis. O período pós-moderno propõe, assim, a desconstrução de preceitos universais, válidos para todos os tempos e para todos os povos, ressaltando a impossibilidade humana de eleição de verdades unívocas - posto que a verdade é sempre parcial e local, mutável e relativa. Todo esse panorama ataca frontalmente a monogamia como forma obrigatória de convivência e de afetividade humana, e ressalta a validade de outras relações entre indivíduos.

O discurso pós-moderno e poliamoroso somente reforça a passagem de paradigma pelo qual a família está atravessando: há uma nebulosa que cerca o conceito e a estrutura da família contemporânea. A entidade familiar está em ebulição, em um processo de mudança e transformação drástico: antigos paradigmas já estabelecidos são confrontados com relevantes dúvidas e ques- 
tionamentos, ao mesmo tempo em que novas formas de convivência humana disputam a validade e o reconhecimento social e estatal. O horizonte da família é incerto: no entanto, todo o debate social que ganha paulatinamente corpo em torno do instituto familiar já se configura como importante passo rumo à ampliação do conceito de família, oportunizando-se a plena realização coletiva dos adeptos do poliamor. 


\section{Referências}

Adovasio, J. M. y Page, J. y Soffer, O. (2008). O sexo invisível. São Paulo: Record.

Bach, J. M. (1983). O futuro da família: tendências e perspectivas. Petrópolis, RJ: Vozes.

Barker, M. (2005). This is my partner, and this is... partner's partner: constructing a polyamorous identity in a monogamous world. Journal of Constructivist Psychology, 18(1), 75-88.

Berman, M. (2007). Tudo que é sólido desmancha no ar: a aventura da modernidade. Carlos Felipe Moisés e Ana Maria L. Ioriatti (trad.). São Paulo: Companhia das Letras.

Bottomore, T. B. (2008). Introdução à sociologia (9a ed.). Waltensir Dutra e Patrick Burglin (trad.). Rio de Janeiro: LTC.

Braun, A. B. M. (2008). Multiculturas, pluralidades, poligamia: o contexto da literatura moçambicana e Niketche, de Paullina Chiziane. Eletras (UTP), $16,1-16$.

Bueno, F. (1996). Minidicionário da língua portuguesa. São Paulo: FTD.

Diniz, M. H. (2004). Curso de direito civil brasileiro: direito de família (vol. 5, 19 ed.). São Paulo: Saraiva.

Emens, E. F. (2003). Monogamy's Law: compulsory monogamy and polyamorous existence. Chicago, Public Law and Legal Theory, Working Paper, (58), 1-85.

Engels, F. (1997). A origem da família, da propriedade privada e do Estado (14 ${ }^{\mathrm{a}}$ ed.). Leandro Konder (trad.). Rio de Janeiro: Bertrand Brasil.

Fachin, L. E. (2003). Direito de família: elementos críticos à luz do novo código civil brasileiro ( $2^{\mathrm{a}}$ ed.). Rio de Janeiro: Renovar. 
Giddens, A. (2001). A terceira via: reflexões sobre o impasse político atual e o futuro da social-democracia ( $4^{\mathrm{a}}$ ed.). Maria Luiza X. de A. Borges (trad.). Rio de Janeiro: Record.

Gonçalves, C. R. (2008). Direito civil brasileiro: direito de família (vol. 6, $5^{\text {a }}$ ed.). São Paulo: Saraiva.

Haritaworn, J., Lin, C. y Klesse, C. (2008). Poly/logue: a critical introduction to polyamory. London, Sexualities, 9(5), 515-529.

Ianni, O. (2001). A sociedade global (9a ed.). Rio de Janeiro: Civilização Brasileira.

Klesse, C. (2008). Polyamory and its 'others': contesting the terms of nonmonogamy. London, Sexualities, 9(5), 565-583.

Kumar, K. (2006). Da sociedade pós-industrial à pós-moderna: novas teorias sobre o mundo contemporâneo ( $2^{\mathrm{a}}$ ed.). Ruy Jungmann (trad.). Rio de Janeiro: Jorge Zahar.

Leach, E. R. (2005). Repensando a antropologia (2 ${ }^{\mathrm{a}}$ ed.). José Luis dos Santos (trad.). São Paulo: Perspectiva.

Leandro, M. E. (2006). Transformações da família na história do Ocidente. Revista Theologica, II série, 41(1), 51-74.

Lessa, S. (2012). A atualidade da abolição da família monogâmica. Revista Crítica Marxista, (35), 41-58.

Oliveira, N. H. D. (2009). Recomeçar: família, filhos e desafios. São Paulo: Editora UNESP.

Pereira, C. M. (2004). Instituições de direito civil (14 ${ }^{\mathrm{a}}$ ed.). Rio de Janeiro: Forense.

Petrini, J. C. y Cavalcanti, V. R. S. (2005). Família, sociedade e subjetividades: uma perspectiva multidisciplinar. Petrópolis, RJ: Vozes. 
Pilão, A. C. y Goldenberg, M. (2012). Poliamor e monogamia: construindo diferenças e hierarquias. Revista Ártemis, 13, 62-73.

Pilão, A. C. (2015). Entre a liberdade e a igualdade: princípios e impasses da ideologia poliamorista. Cadernos Pagu, (44), 391-422.

Quadros, T. de A. (2004). O princípio da monogamia e o concubinato adulterino. Teresina, Jus Navigandi, (412).

Rabelo, C. M. de A. y Poli, L. M. (2015). O reconhecimento da família poliafetiva no Brasil: uma análise à luz dos princípios da dignidade humana, autonomia privada, pluralismo familiar e isonomia. Revista Duc In Altum Cadernos de Direito, 7(13), 54-99.

Rodrigues, S. (2004). Direito civil: direito de família (vol. 6, $28^{\mathrm{a}}$ ed.). São Paulo: Saraiva.

Rotondano, R. (2013). Investigando a herança cultural-religiosa brasileira: a dificuldade em instituir um Estado plenamente laico. Londrina, Revista do Direito Público, 8(2), 221-238.

Rotondano, R. O. (2016). Cultura e ética na formação familiar: a poligamia e a sua repressão no ocidente. Revista Bioética y Derecho, (38), 87-99.

Roudinesco, E. (2002). La famillie em désordre. Paris: Fayard.

Santa Maria, J. S. de (2001). Curso de direito civil: direito de família. Rio de Janeiro: Freitas Bastos.

Santos, B. de S. (2002). Para um novo senso comum: a ciência, o direito e a política na transição paradigmática ( $4^{\mathrm{a}}$ ed.). São Paulo: Cortez.

Silva, A. B. da (2016). Escrituras para uniões poliafetivas: algumas impressões sobre mais essa novidade no direito das famílias. Canoas, REDES - Revista Eletrônica Direito e Sociedade, 4(2), 313-352. 
Vaitsman, J. (1994). Flexíveis e plurais: identidade, casamento e família em circunstâncias pós-modernas. Rio de Janeiro: Rocco.

Venosa, S. de S. (2004). Direito civil: direito de família (4ª ed.). São Paulo: Atlas.

Veras, É. V. C. O (2013). Famílias simultâneas: um diálogo sócio-jurídico. Natal, Revista FIDES, 4(2), 71-98.

Wolkmer, A. C. (2001). Pluralismo jurídico: fundamentos de uma nova cultura no direito ( $3^{\mathrm{a}}$ ed.). São Paulo: Alfa Omega.

\section{Notas}

${ }^{1}$ Neste ponto, converge o início histórico da submissão feminina ao homem na sociedade, em que a objetificação da mulher a coloca em um patamar de inferioridade social, física, psicológica, sexual e afetiva frente ao sujeito masculino. Tal paradigma vigora até os dias atuais, não obstante haja a ilusória disseminação do discurso de horizontalidade das relações entre mulheres e homens.

${ }^{2}$ Equivocadamente, Cláudia Mara de Almeida Rabelo e Leonardo Macedo Poli (O reconhecimento da família poliafetiva no Brasil: uma análise à luz dos princípios da dignidade humana, autonomia privada, pluralismo familiar e isonomia. Revista Duc In Altum Cadernos de Direito, v. 7, n. 13, pp. 54-99, set./dez. 2015, p. 66-67) consideram que "o poliamor encontra resistência pelo fato de o núcleo central ser formado por mais de duas pessoas, com ou sem diversidade de gênero".

${ }^{3}$ Haritaworn, Jin; Lin, Chin-ju; Klesse, Christian. Poly/logue: a critical introduction to polyamory. Sexualities, London, v. 9, n. 5, pp. 515-529, 2008, p. 520: "Self-knowledge is described as the sine qua non of a successful polyamorous relationship life, as much as honesty, disclosure, partner-focused techniques of communication, and the readiness for permanent negotiation".

${ }^{4}$ As comunidades islâmicas adotam como modelo preferencial, inclusive, a endogamia, que é o casamento entre os indivíduos do próprio povo (Leach, 
Edmund Ronald. Repensando a antropologia. Tradução: José Luis dos Santos. $2^{\mathrm{a}}$ edição. São Paulo: Perspectiva, 2005, p. 168).

${ }^{5}$ Importante ressaltar que a concepção pós-modernista não é uma unanimidade entre os estudiosos da área, levantando dúvidas sobre a sua existência. Alguns autores acreditam que os caracteres de desconstrução e anarquia identificados como pós-modernidade são, na verdade, o estágio mais atual da modernidade, que ainda está em evidência: "No século XX, nossa terceira e última fase, o processo de modernização se expande a ponto de abarcar virtualmente o mundo todo, e a cultura mundial do modernismo em desenvolvimento atinge espetaculares triunfos na arte e no pensamento. Por outro lado, à medida que se expande, o público moderno se multiplica em uma multidão de fragmentos, que falam linguagens incomensuravelmente confidenciais; a idéia de modernidade, concebida em inúmeros e fragmentários caminhos, perde muito de sua nitidez, ressonância e profundidade e perde sua capacidade de organizar e dar sentido à vida das pessoas. Em conseqüência disso, encontramo-nos hoje em meio a uma era moderna que perdeu contato com as raízes de sua própria modernidade" (Berman, Marshall. Tudo que é sólido desmancha no ar: a aventura da modernidade. Tradução: Carlos Felipe Moisés e Ana Maria L. Ioriatti. São Paulo: Companhia das Letras, 2007, p. 26).

${ }^{6}$ Tal processo é alcunhado de ocidentalização do mundo pelo sociólogo Octavio Ianni (A sociedade global. $9^{a}$ edição. Rio de Janeiro: Civilização Brasileira, 2001, pp. 74-75), produzindo uma espécie de mundialização da indústria cultural, reeducando povos, nações e continentes: "Um sintoma muito característico da forma pela qual ocorre o novo ciclo de ocidentalização do mundo está no fato de que a língua inglesa se tornou uma língua universal. É usado não somente entre europeus e norte-americanos, por um lado, e asiáticos, africanos e latino-americanos, por outro. É usada também entre diferentes povos africanos, asiáticos e latino-americanos, quando necessitam comunicar-se entre si. E há países, como a Índia, por exemplo, em que o inglês é a língua nacional de fato. Toda a matéria fundamental para a vida pública, no que se refere a questões políticas, econômicas, sociais e culturais, é tratada em inglês. Os próprios debates sobre as línguas regionais e o hindu, esta a língua nacional oficial segundo a Constituição, realizam-se também em inglês".

${ }^{7}$ Há ainda quem vislumbre o retorno da instituição familiar ao seio do modelo 
cristão, após a revitalização do cristianismo: "Estamos certos de que se, por um lado, as Religiões se desviaram por vezes, por vias tortuosas ou em refratárias alianças, perdendo substância e prestígio, por outro lado, avançam as pesquisas científicas adentrando-se na Parapsicologia para a revolucionária descoberta da essência espiritual do homem. Esta descoberta dará às Religiões as bases racionais para novas e promissoras construções, uma nova arquitetura ética que realizará o bem comum, através da instituição familiar. Tudo isto fará a família retornar a sua importância e maior vitalidade sob as luzes do mais puro Cristianismo, como uma instituição divina, como uma preciosa oficina de edificação ética do homem do futuro" (Santa Maria, José Serpa de. Curso de direito civil: direito de família. Rio de Janeiro: Freitas Bastos, 2001, p. 19).

${ }^{8} \mathrm{O}$ pesquisador Anthony Giddens (A terceira via: reflexões sobre o impasse político atual e o futuro da social-democracia. Tradução: Maria Luiza X. de A. Borges. $4^{a}$ edição. Rio de Janeiro: Record, 2001, p. 99) classifica este conjunto de transformações como um colapso necessário da família: "Muitos agora falam do colapso da família. Se tal colapso está ocorrendo, ele é extremamente importante. A família é o ponto de encontro de uma gama de tendências que afetam a sociedade como um todo - igualdade crescente entre os sexos, o ingresso generalizado de mulheres na força de trabalho, mudanças no comportamento e nas expectativas sexuais, a mudança na relação entre casa e trabalho".

${ }^{9}$ Nayara Oliveira (Recomeçar: família, filhos e desafios. São Paulo: Editora UNESP, 2009, p. 68) exemplifica: "A composição pode variar em uniões consensuais de parceiros separados ou divorciados; uniões de pessoas do mesmo sexo; uniões de pessoas com filhos de outros casamentos; mães sozinhas com seus filhos, sendo cada um de um pai diferente; pais sozinhos com seus filhos; avós com os seus netos; e uma infinidade de formas a serem definidas, colocando-nos diante de uma nova família, diferenciada do clássico modelo de família nuclear". 